\title{
Estrutura sinusial dos componentes herbáceo e arbustivo de uma floresta costeira subtropical ${ }^{1}$
}

\author{
SANDRA CRISTINA MÜLLER ${ }^{2,3}$ e JORGE LUIZ WAECHTER ${ }^{2}$
}

(recebido: 6 de dezembro de 2000; aceito: 19 de julho de 2001)

\begin{abstract}
Synusial structure of the herb and shrub components of a coastal subtropical forest). The herb and shrub synusiae are little known components of forest communities in tropical and subtropical regions. The floristic composition and phytosociological structure of these synusiae were studied in a dune forest (restinga) of the Coastal Plain of Rio Grande do Sul, Brazil. Synusial composition and structure were recorded for 30 sample plots of $2 \times 2 \mathrm{~m}$. In each plot, presence and maximum height for herb and shrub species were recorded, and cover was estimated according to Causton's scale. There were 61 species, 52 genera and 33 families in the area. Families with more than two species were: Poaceae, Commelinaceae, Orchidaceae, Piperaceae, Rubiaceae and Asteraceae. The life-forms of most species were hemicryptophytes and chamaephytes. The phytosociological sampling resulted in 26 herbaceous and 10 shrubby species, pertaining to 31 genera and 24 families. The most important species were Carex sellowiana Schlecht., Oplismenus hirtellus (L.) P. Beauv., Spathicarpa hastifolia Hook. (herbs), Pavonia sepium St.-Hil. and Justicia brasiliana Roth (shrubs). Species diversity and evenness, using Shannon's (H') and Pielou's $(\mathrm{J})$ indexes estimated from frequency, were 2.98 and 0.84 , respectively.
\end{abstract}

RESUMO - (Estrutura sinusial dos componentes herbáceo e arbustivo de uma floresta costeira subtropical). As sinúsias herbáceas e arbustivas são componentes de comunidades florestais pouco pesquisados nas regiões tropicais e subtropicais. Neste trabalho foram estudadas a composição florística e a estrutura fitossociológica destas sinúsias em uma floresta arenosa (restinga) da Planície Costeira do Rio Grande do Sul, Brasil. Os dados fitossociológicos foram obtidos em 30 parcelas de $2 \times 2 \mathrm{~m}$. Em cada parcela anotou-se a presença e a altura máxima das espécies herbáceas e arbutivas, e a cobertura foi estimada pela escala de Causton. A composição florística total da área compreende 61 espécies, 52 gêneros e 33 famílias. As famílias que apresentaram mais de duas espécies foram: Poaceae, Commelinaceae, Orchidaceae, Piperaceae, Rubiaceae e Asteraceae. As formas de vida hemicriptófita e caméfita foram as mais representativas. A amostragem fitossociológica resultou em 26 espécies herbáceas e 10 arbustivas, pertencentes a 31 gêneros e 24 famílias. As espécies mais importantes foram Carex sellowiana Schlecht., Oplismenus hirtellus (L.) P. Beauv., Spathicarpa hastifolia Hook. (herbáceas), Pavonia sepium St.-Hil. e Justicia brasiliana Roth (arbustos). A diversidade e eqüidade específica, segundo os índices de Shannon (H') e Pielou (J) estimados pela freqüência, foram 2,98 e 0,84 , respectivamente.

Key words - Herbs, shrubs, "restinga", diversity, life-forms

\section{Introdução}

Em florestas tropicais e subtropicais, estudos florísticos e fitossociológicos são, principalmente, direcionados ao componente arbóreo (Gentry 1992, Martins 1993). A contribuição de espécies não arbóreas na diversidade tem sido observada, sendo que o número de espécies herbáceas e subarbustivas, em flórulas completas de florestas, pode variar de 33 a $52 \%$ da riqueza específica, enquanto as espécies arbóreas (DAP $\geq 10 \mathrm{~cm}$ ) constituem de 15 a $22 \%$ (Gentry \& Dodson 1987).

1. Parte da dissertação de mestrado no Programa de Pósgraduação em Botânica da Universidade Federal do Rio Grande do Sul (UFRGS).

2. UFRGS, Departamento de Botânica, Av. Paulo Gama, 40, 90046-900 Porto Alegre, RS, Brasil.

3. Autor para correspondência: smuller@ecologia.ufrgs.br
O conhecimento da estrutura e composição dos estratos inferiores de florestas pode fornecer dados para inferir sobre as condições ambientais e o estado de conservação de comunidades florestais (Richards 1952), pois espécies herbáceas e arbustivas florestais apresentam adaptações estruturais e fisiológicas associadas ao ambiente em que vivem (Givnish 1986). Espécies do sub-bosque são sensíveis às mudanças climáticas e edáficas, às características do estrato arbóreo e aos distúrbios antrópicos de uma comunidade, mostrando alterações na riqueza específica e na densidade populacional (Veblen et al. 1979, Poulsen 1996, Turner et al. 1996).

No Brasil, os estudos sobre comunidades de herbáceas e arbustos florestais também são ainda escassos. Na região sul, dados sobre espécies herbáceas e arbustivas florestais são encontrados em levantamentos florísticos (Cain et al. 1956, Baptista \& Irgang 1972, Knob 1978), em estudos dos 
estratos herbáceo e arbustivo (Diesel 1991), ou ainda exclusivos do estrato ou componente herbáceo (Citadini-Zanette 1984, Cestaro et al. 1986, CitadiniZanette \& Baptista 1989, Dorneles \& Negrelle 1999).

A vegetação costeira do Rio Grande do Sul apresenta uma diversidade de ambientes que proporciona a formação de um mosaico de comunidades vegetais distintas florística e fisionomicamente, desde formações campestres e banhados até formações arbóreas (Veloso \& Klein 1963, Pfadenhauer 1980, Waechter 1985, Cordazzo \& Seeliger 1987). As formações arbóreas, florestas de restinga, sofrem influência florística das demais formações florestais adjacentes que se encontram em solos geologicamente mais antigos (Rambo 1954, Waechter 1985, 1990). Descrições florísticas e fitossociológicas do componente arbóreo em florestas de restinga podem ser obtidas em Porto \& Dillenburg (1986), Dillenburg et al. (1992), Rossoni \& Baptista (1994) e Waechter \& Jarenkow (1998), nas quais apenas são mencionadas as espécies herbáceas e arbustivas mais comuns.

O presente estudo objetiva caracterizar a estrutura das sinúsias herbácea e arbustiva de uma floresta costeira subtropical através da composição florística, classificação em formas de vida e estimativa de parâmetros fitossociológicos das espécies. O termo sinúsia é utilizado por denominar um conjunto de plantas semelhantes na forma e no hábito e que requerem condições microclimáticas também idênticas ao seu crescimento e desenvolvimento numa comunidade vegetal (Richards 1952, Braun-Blanquet 1979, Rizzini 1997). O presente estudo é parte de uma dissertação de mestrado (Müller 1999) que integra uma abordagem mais ampla, incluindo os componentes epifítico vascular (Breier 1999), apoiante-escandente (Venturi 2000) e arbóreo (Waechter et al. 2000), na floresta de Morro Grande.

\section{Material e métodos}

Área de estudo - A área se encontra a cerca de $30^{\circ} 05^{\prime} \mathrm{S}$ e $50^{\circ} 50^{\prime} \mathrm{W}$, na localidade de Morro Grande, município de Viamão, Rio Grande do Sul. O estudo foi realizado em dois remanescentes florestais situados sobre a Barreira das Lombas, distando aproximadamente $60 \mathrm{~km}$ do oceano Atlântico e com altitudes que variam de 20 a $50 \mathrm{~m}$ (figura 1). Os remanescentes florestais são denominados no texto como floresta de Morro Grande, tomando como referência ao nome da localidade e o principal acidente geográfico da região, o Morro Grande (107 m).

O clima da região é subtropical úmido com verões quentes e sem estação seca definida (Nimer 1979), porém com períodos de déficit hídrico no verão devido ao aumento da temperatura
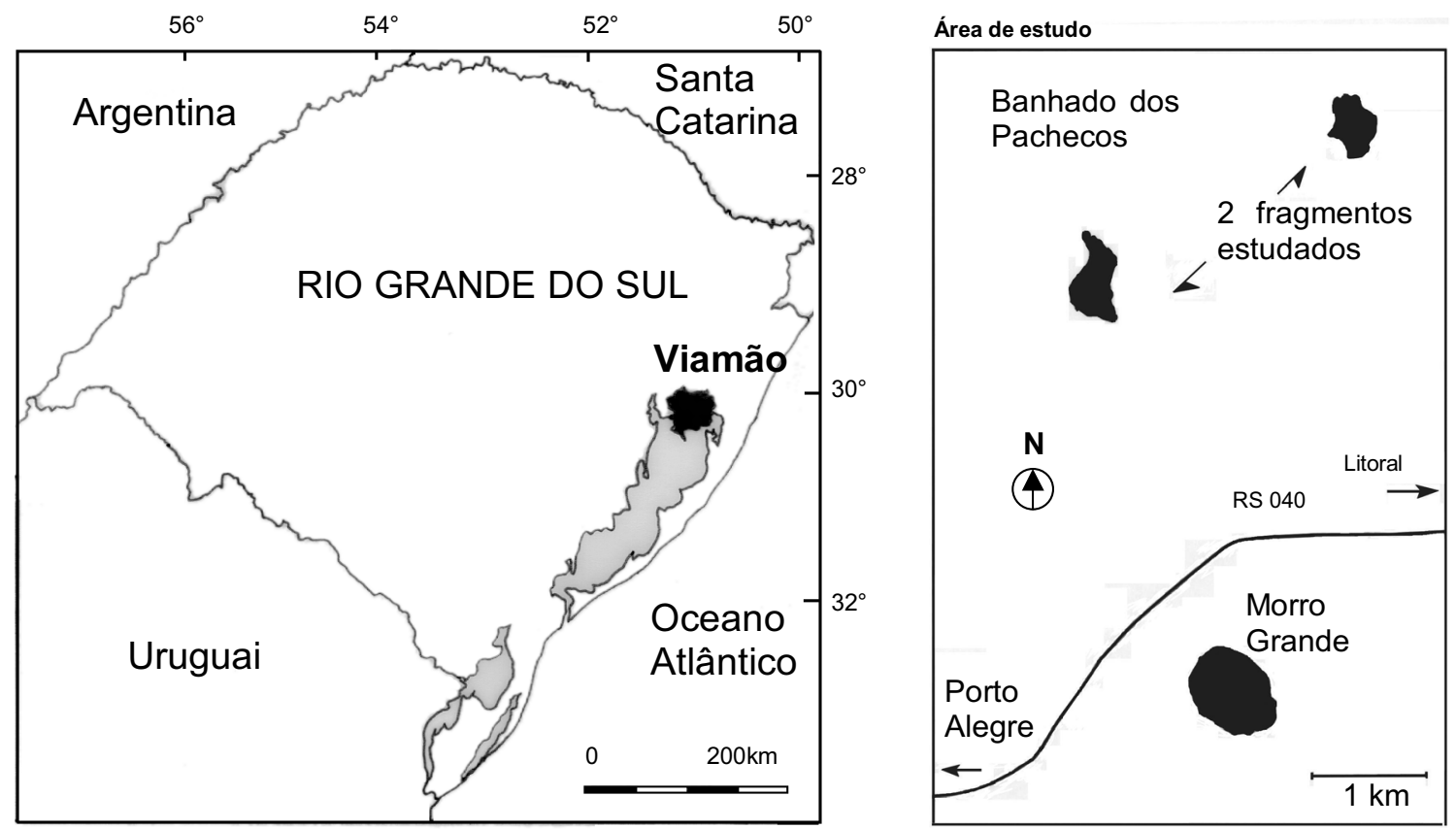

Figura 1. Localização do município de Viamão no Rio Grande do Sul (Fonte: Secretaria da Coordenação e Planejamento - RS, 1998) e da área de estudo, aproximadamente $30^{\circ} 05^{\prime} \mathrm{S}$ e $50^{\circ} 50^{\prime} \mathrm{W}$, na localidade de Morro Grande (Fonte: adaptado de uma foto aérea tirada pela Força Aérea Brasileira, na proporção 1:40.000). 
média e da intensidade de radiação solar (Mota et al. 1970). Segundo o sistema de Köppen, é do tipo Cfa com temperatura e precipitação média anual em torno de $19^{\circ} \mathrm{C}$ e $1300 \mathrm{~mm}$, respectivamente (Moreno 1961).

A Barreira das Lombas é descrita como o primeiro sistema deposicional, 'Sistema Laguna/Barreira I', que integra um conjunto de fácies sedimentares descontínuas no espaço e no tempo devido às variações globais do nível do mar, porém agrupadas ao longo da Planície Costeira do Rio Grande do Sul (Villwock 1984). Atualmente, a Barreira das Lombas é reconhecida como uma faixa alongada na direção nordestesudoeste com cerca de $250 \mathrm{~km}$, constituída por depósitos de areia que formam coxilhas arredondadas com altitudes de 40 a $150 \mathrm{~m}$ (Herrmann \& Rosa 1990). O solo do local pertence à unidade de mapeamento Itapoã (solos profundos, podzolizados, arenosos e bem drenados) classificado como Podzólico Vermelho-Amarelo Abrúptico (Lemos et al. 1973).

As comunidades vegetais dessa área pertencem à região fisiográfica do Litoral e à região geomorfológica da Planície Costeira (Delaney 1965). A diversidade de formações geomorfológicas, as variações microclimáticas e os fatores temporais de sucessão e da história geológica caracterizam diferentes tipos vegetacionais no litoral sul-rio-grandense. $\mathrm{O}$ conjunto todo é denominado 'Complexo de Restinga', segundo o Sistema de Unidades Fitogeográficas do Brasil (Rizzini 1997). Estudos locais definem nove tipos principais de vegetação de restinga para o Rio Grande do Sul, entre os quais os remanescentes estudados se assemelham às Matas Arenosas (Waechter 1985, 1990).

Nos mesmos remanescentes florestais, Waechter et al. (2000) estudaram o componente arbóreo. Neste estudo, a composição florística e a estrutura espacial demonstraram uma transição entre florestas subtropicais sobre depósitos arenosos costeiros (restingas) e florestas interiores de encosta (semidecíduas), tendo como espécies mais importantes, Patagonula americana, Sebastiania commersoniana, Chrysophyllum marginatum, Sideroxylon obtusifolium, Ficus organensis, Casearia sylvestris e Allophylus edulis. As florestas se caracterizam pelo porte relativamente baixo (média $=10,89 \mathrm{~m}$ de altura), onde indivíduos de Ficus organensis, Cordia trichotoma e Patagonula americana podem se destacar como emergentes.

Métodos - O reconhecimento a campo de espécies herbáceas e arbustivas terrícolas foi baseado, principalmente, na consistência herbácea ou lenhosa dos ramos aéreos. Como espécies arbustivas foram incluídas plantas que se ramificam desde a base ou se assemelham a árvores em miniatura, porém sem ultrapassar três metros de altura. Espécies subarbustivas, com ramos basais lenhosos e apicais herbáceos, também foram diferenciadas. Posteriormente, o hábito das espécies no estádio adulto foi confirmado em trabalhos taxonômicos.

O inventário florístico foi realizado em toda a área de abrangência dos dois remanescentes florestais selecionados, com enfoque às observações no interior das florestas. A classificação taxonômica seguiu as propostas de Tryon \& Tryon (1982) para Pteridophyta e de Cronquist (1988) para Magnoliophyta. As exsicatas foram incorporadas ao acervo do Herbário do Departamento de Botânica da Universidade Federal do Rio Grande do Sul (ICN).

A coleta de dados florísticos e fitossociológicos foi realizada de agosto de 1997 a janeiro de 1999. No estudo fitossociológico foi empregado o método de parcelas. Para tanto, foram traçadas seis transecções de $50 \mathrm{~m}$, três em cada fragmento florestal. A cada $10 \mathrm{~m}$ foi marcado um ponto e então fixada uma parcela de $2 \times 2 \mathrm{~m}$ (unidade amostral). A escolha do mesmo tamanho de unidade amostral para as sinúsias herbácea e arbustiva foi decidida em função das características fisionômicas previamente observadas no local de estudo, entre elas, o baixo número de espécies e indivíduos arbustivos, bem como sua baixa estatura (ca. $150 \mathrm{~cm})$, a presença de espécies subarbustivas e a presença de herbáceas de porte relativamente grande. A área total amostrada foi $120 \mathrm{~m}^{2}$, equivalente a 30 parcelas. Em cada parcela foram anotados os dados de presença, altura máxima e cobertura das espécies herbáceas ou arbustivas. A cobertura foi estimada segundo a escala proposta por Causton (1988), com cinco 'classes de cobertura' que avaliam, em porcentagem, a projeção da parte aérea da planta na superfície da parcela.

Freqüência e cobertura, absolutas e relativas, e o valor de importância foram os parâmetros fitossociológicos estimados para esta comunidade, conforme as seguintes equações:

$\mathrm{FA}_{\mathrm{i}}=100\left(\mathrm{~Np}_{\mathrm{i}} / \mathrm{Np}_{\mathrm{t}}\right)$

$\mathrm{FR}_{\mathrm{i}}=100\left(\mathrm{FA}_{\mathrm{i}} / \mathrm{S} \mathrm{FA}_{\mathrm{i}}\right)$ onde: $\mathrm{FA}_{\mathrm{i}}=$ freqüência absoluta da espécie $\mathrm{i}, \mathrm{Np}_{\mathrm{i}}=$ número de parcelas com a espécie i, $\mathrm{Np}_{\mathrm{t}}=$ número total de parcelas, $\mathrm{FR}_{\mathrm{i}}=$ freqüência relativa da espécie $i$,

$\mathrm{CA}_{\mathrm{i}}=\Sigma \mathrm{Ccob}_{\mathrm{i}}$

$\mathrm{CR}_{\mathrm{i}}=100\left(\mathrm{CA}_{\mathrm{i}} / \Sigma \mathrm{CA}_{\mathrm{i}}\right)$

$\mathrm{CA}_{\mathrm{i}}=$ cobertura absoluta da espécie $\mathrm{i}, \mathrm{Ccob}_{\mathrm{i}}=$ classes de cobertura (nos intervalos de 1 a 5) estimadas para a espécie i, $\mathrm{CR}_{\mathrm{i}}=$ cobertura relativa da espécie i,

$\mathrm{VI}=\left(\mathrm{CR}_{\mathrm{i}}+\mathrm{FR}_{\mathrm{i}}\right) / 2 \quad \mathrm{VI}=$ valor de importância

As espécies do levantamento florístico foram agrupadas em formas de vida com base no sistema de Raunkiaer, modificado por Mueller-Dombois \& Ellenberg (1974). Espécies com rizomas superficiais (Olyra humilis, Pharus lappulaceus e algumas samambaias), expostos ou cobertos apenas por serapilheira, foram classificadas como hemicriptófitas, seguindo Citadini-Zanette (1984) e Senna \& Waechter (1997). As formas de vida foram subdivididas em grupos denominados 'formas de crescimento', as quais refletem características fisionômicas e morfológicas das espécies em relação às respostas do ambiente local (Whittaker 1975, Braun-Blanquet 1979).

Como indicadores de diversidade foram utilizados os parâmetros de riqueza específica (S), índice de diversidade de Shannon (H'), com base no logarítmo natural (nats), e índice de eqüidade (E) (Pielou 1969, Whittaker 1972). A participação quantitativa das espécies para a estimativa dos índices foi avaliada pelos valores de freqüência, uma vez que não foi estimada a densidade devido à subjetividade em distinguir indivíduos em algumas espécies herbáceas reptantes. A uso da freqüência como parâmetro indicativo de abundância geralmente tende a uma subestimativa dos valores das espécies mais comuns (Magurran 1988). Por este motivo verificou-se a relação da freqüência com a cobertura (outra medida de abundância avaliada no presente levantamento) através da análise de correlação direta em um gráfico de dispersão $(\mathrm{x}, \mathrm{y})$. 
Para a discussão da diversidade, optou-se pela estimativa e comparação da diversidade do componente herbáceo e herbáceo-arbustivo de outras comunidades florestais do Rio Grande do Sul, empregando-se o teste $t$ de variância de H' (Magurran 1988) na avaliação de diferenças significativas. Para tanto, foram utilizados os valores de $p i$ (presença da espécie nas unidades amostrais) obtidos nos levantamentos fitossociológicos dos trabalhos de Knob (1978), CitadiniZanette (1984), Cestaro et al. (1986), Citadini-Zanette \& Baptista (1989) e Diesel (1991).

\section{Resultados}

A composição da flora herbácea e arbustiva terrícola de toda a área estudada resultou em 61 espécies, 52 gêneros e 33 famílias (tabela 1). A sinúsia arbustiva foi representada por apenas 14 espécies, pertencentes a nove famílias. Essas famílias, com exceção de Rubiaceae, não

Tabela 1. Lista florística, formas de vida e número do registro do coletor (S.C. Müller) das espécies herbáceas (h) e arbustivas (a) terrícolas da floresta de Morro Grande, Viamão, RS. Caméfita arbustiva (Carb), subarbustiva (Csub) e herbácea (Cher); Hemicriptófita rosulada (Hros), reptante (Hrep), cespitosa (Hces); Geófita rizomatosa (Griz) e bulbosa (Gbul); Terófita escaposa (Tesc).

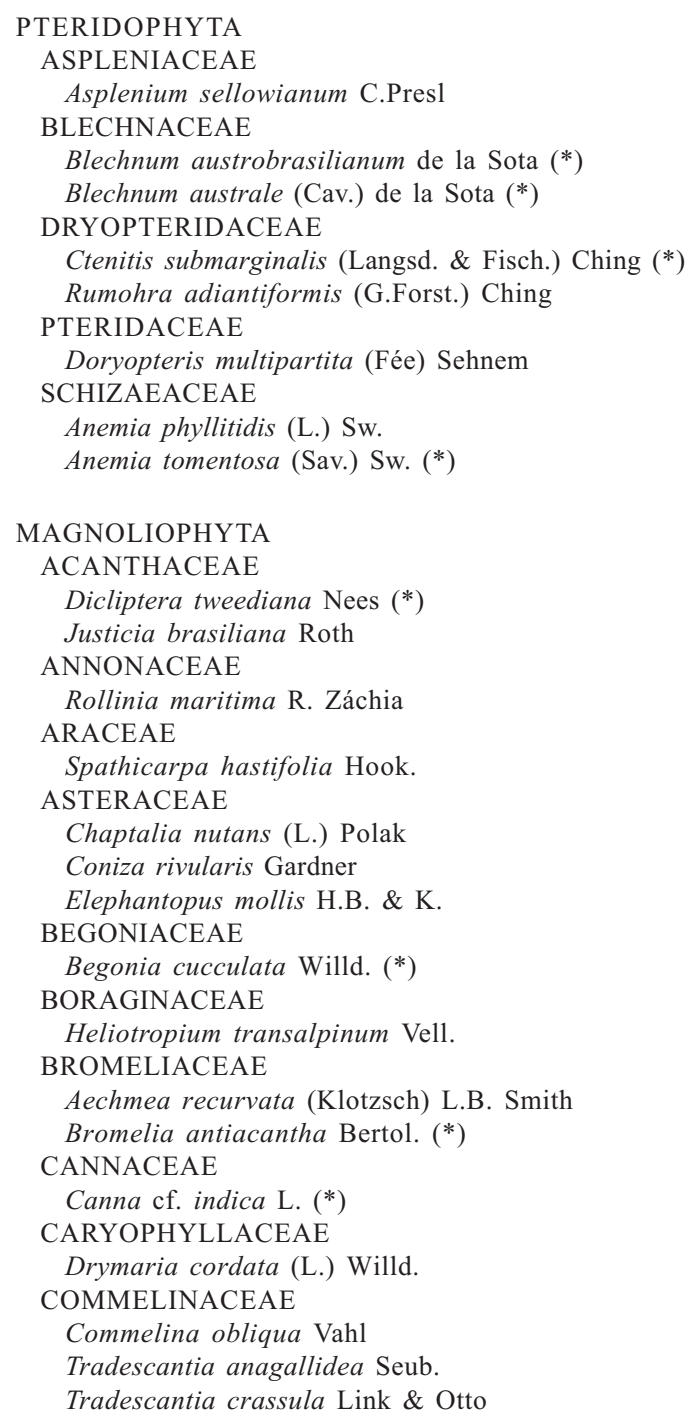

Tradescantia anagallidea Seub.

(h)

(h)

(h)

(h)

(h)

(a)

(a)

(h)

(a)
Hros

012

Hros

Hros

$108^{\mathrm{B}}$

055

056

$\begin{array}{ll}\text { Hros } & 056 \\ \text { Griz } & 032\end{array}$

Hces

017

Griz

Griz

Carb

Hros

Hros 
Tradescantia fluminensis Vell.

CONVOLVULACEAE

Dichondra microcalyx (H. Hallier) Fabris (*)

CYPERACEAE

Carex sellowiana Schlecht.

Cyperus incomtus Kunth (*)

FABACEAE

Desmodium affine Schlecht.

LAMIACEAE

Ocimum selloi Benth.

LILIACEAE

Hippeastrum sp. (*)

LOGANIACEAE

Spigelia humboldtiana Cham. \& Schlecht. (*)

MALVACEAE

Pavonia sepium St.-Hil. (*)

MARANTACEAE

Maranta arundinacea L. (*)

MELASTOMATACEAE

Leandra australis (Cham.) Cogn. (*)

Miconia hyemalis St.-Hil. (*)

ORCHIDACEAE

Cyclopogon elatus (Sw.) Schlechter (*)

Galeandra beyrichii Reichb. f. (*)

Hapalorchis micranthus (Bar. Rodr.) Hoehne

Mesadenella cuspidata (Lindl.) L.A. Garay

OXALIDACEAE

Oxalis articulata Savign.

Oxalis linarantha A. Lourteig

PHYTOLACCACEAE

Petiveria alliacea L.

PIPERACEAE

Peperomia blanda H.B. \& K.

Peperomia caulibarbis Miq.

Peperomia pereskiaefolia H.B. \& K.

Piper dilatatum Rich.

POACEAE

Homolepis glutinosa (Sw.) Zuloaga \& Soderstr.

Olyra humilis Ness (*)

Oplismenus hirtellus (L.) P.Beauv.

Panicum sellowii Nees (*)

Paspalum inaequivalve Raddi (*)

Pharus lappulaceus Aubl. (*)

Pseudechinolaena polystachya Stapf.

PORTULACACEAE

Talinum paniculatum (Jacq.) Gaertn. (*)

RUBIACEAE

Coccocypselum lanceolatum Pers. (*)

Coccocypselum cf. condalia Pers. (*)

Psychotria brachyceras Muell. Arg. (*)

Psychotria carthagenensis Jacq.

SOLANACEAE

Cestrum strigilatum Ruiz \& Pavon

TILIACEAE

Triumfetta semitriloba L. (h)

Hrep

038

(h)

Hrep

045

(h)

Hces

015

(h)

Hces

036

(h)

Cher

023

(a)

Csub

021

(h)

(h)

Gbul

s/c

049

(a)

Cher

028

(h)

Csub

022

(a)

(a)

(h)

(h)

(h)

(h)

(h)

(h)

(a)

(h)

(h)

(h)

(a)

(h)

(h)

(h)

(h)

(h)

(h)

(h)

(h)

(h)

(h)

(a)

(a)

(a)

(a)

Griz

047

Carb

062

Carb

004

Hros

058

005

006

Hros

048

Griz

010

031

Csub

009

Hrep

008

007

Hrep

044

Carb

018

Hces

046

013

025

024

051

014

Hces

Hrep

057

Tesc

050

Cher

061

033

Carb

034

Carb

053

Carb

029

$(*)=$ espécie não registrada na amostragem fitossociológica. ${ }^{\mathrm{B}}=$ registro do coletor T.B. Breier; s/c $=$ sem coleta, porém observada na mata. 
a) Levantamento florístico

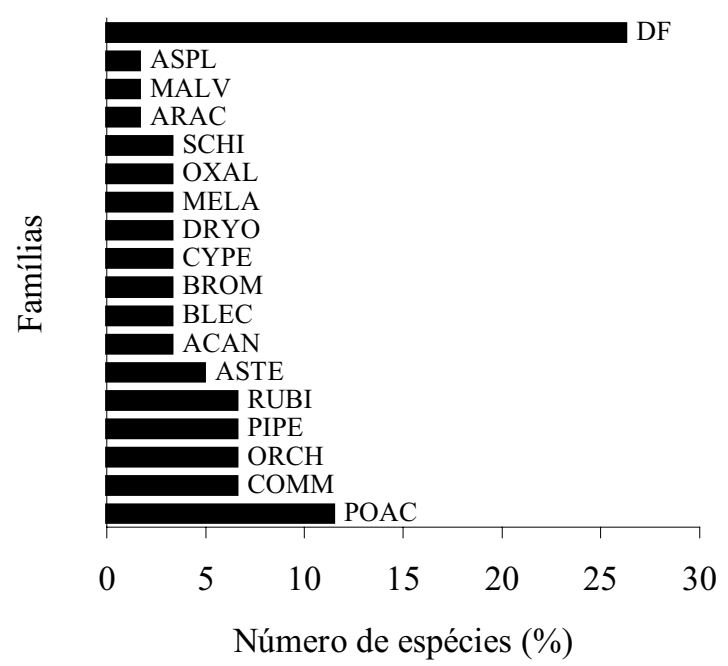

b) Levantamento fitossociológico

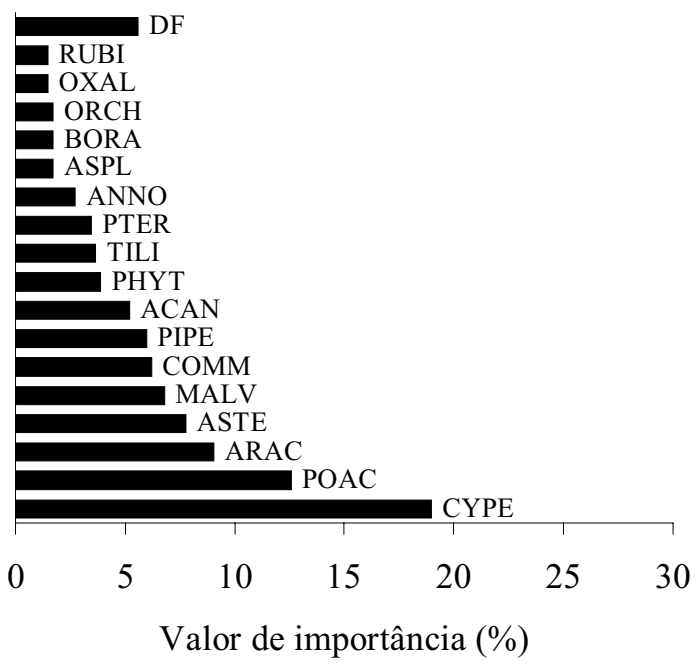

Figura 2. Participação das famílias no levantamento florístico (a) e fitossociológico (b) das espécies herbáceas e arbustivas terrícolas na floresta arenosa de restinga em Morro Grande, Viamão, RS. Os acrônimos correspondem as quatro letras inicias das famílias da tabela 1 e DF = demais famílias.

apresentaram espécies herbáceas terrícolas neste levantamento.

A sinúsia herbácea foi representada por 47 espécies: oito pteridófitas (13,1\%), 23 de Liliopsida (Monocotiledôneas) e 16 de Magnoliopsida (Dicotiledôneas). Poaceae apresentou o maior número de espécies (11,5\%), seguida por Orchidaceae, Commelinaceae, Piperaceae, Rubiaceae e Asteraceae (figura 2a). Entretanto, o destaque maior de Poaceae ocorre apenas quando considerado todo o levantamento florístico realizado na área de estudo, pois na amostragem fitossociológica, Commelinaceae, Piperaceae e Asteraceae aparecem com número semelhante de espécies. As demais famílias apresentaram apenas duas ou uma espécie e foram equivalentes a $57,6 \%$.

A classificação em formas de vida (tabela 1) revelou que a maioria das espécies presentes (52\%) pertence às hemicriptófitas, seguindo-se caméfitas (30\%), geófitas $(16 \%)$ e terófitas $(1,6 \%)$. As formas de crescimento hemicriptófitas reptantes e rosuladas formaram os grupos com maior número de espécies na floresta estudada (figura 3).

No levantamento fitossociológico foram amostradas 36 espécies, 31 gêneros e 24 famílias (tabela 2). A participação das famílias na amostragem fitossociológica (figura 2b) refletiu claramente os valores individuais das espécies, mostrando uma ordem diferente da observada na participação florística (figura 2a). Cyperaceae, Araceae e Asteraceae, por exemplo, apresentaram valor de importância alto decorrente de apenas uma espécie, respectivamente, Carex sellowiana, Spathicarpa hastifolia e Chaptalia nutans. Também sob esta avaliação, se

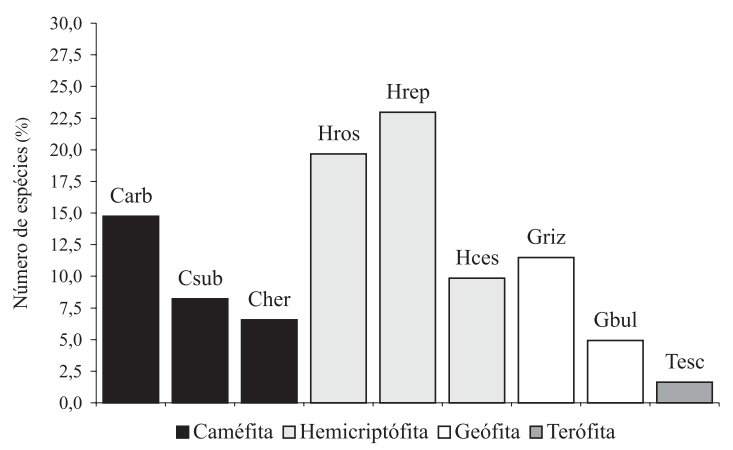

Figura 3. Porcentagem das formas de crescimento das espécies herbáceas terrícolas e arbustivas da floresta de Morro Grande, Viamão, RS. Ver a referência dos acrônimos na tabela 1. 
Tabela 2. Parâmetros fitossociológicos estimados e altura máxima observada para as espécies herbáceas e arbustivas na floresta de Morro Grande, Viamão, RS: número de parcelas com a espécie i $\left(\mathrm{Np}_{\mathrm{i}}\right)$; altura máxima (hmáx. $\left.{ }_{\mathrm{i}}\right)$; freqüência absoluta $\left(\mathrm{FA}_{\mathrm{i}}\right)$ e relativa $\left(\mathrm{FR}_{\mathrm{i}}\right)$; cobertura absoluta $\left(\mathrm{CA}_{\mathrm{i}}\right)$ e relativa $\left(\mathrm{CR}_{\mathrm{i}}\right)$ e valor de importância $(\mathrm{VI})$.

\begin{tabular}{|c|c|c|c|c|c|c|c|}
\hline ESPÉCIE & $\mathrm{Np}_{\mathrm{i}}$ & hmáx. $_{\cdot \mathrm{i}}(\mathrm{cm})$ & $\mathrm{FA}_{\mathrm{i}}$ & $\mathrm{FR}_{\mathrm{i}}$ & $\mathrm{CA}_{\mathrm{i}}$ & $\mathrm{CR}_{\mathrm{i}}$ & VI \\
\hline Carex sellowiana & 30 & 23 & 100,00 & 14,49 & 62 & 23,48 & 18,99 \\
\hline Oplismenus hirtellus (*) & 25 & 9 & 83,33 & 12,08 & 29 & 10,98 & 11,53 \\
\hline Spathicarpa hastifolia & 21 & 40 & 70,00 & 10,14 & 21 & 7,95 & 9,05 \\
\hline Chaptalia nutans & 16 & 17 & 53,33 & 7,73 & 16 & 6,06 & 6,90 \\
\hline Pavonia sepium & 14 & 105 & 46,67 & 6,76 & 18 & 6,82 & 6,79 \\
\hline Justicia brasiliana & 9 & 222 & 30,00 & 4,35 & 16 & 6,06 & 5,20 \\
\hline Tradescantia fluminensis & 11 & 13 & 36,67 & 5,31 & 12 & 4,55 & 4,93 \\
\hline Peperomia pereskiaefolia & 10 & 35 & 33,33 & 4,83 & 10 & 3,79 & 4,31 \\
\hline Petiveria alliacea & 9 & 35 & 30,00 & 4,35 & 9 & 3,41 & 3,88 \\
\hline Triumfetta semitriloba & 8 & 95 & 26,67 & 3,86 & 9 & 3,41 & 3,64 \\
\hline Doryopteris multipartita & 8 & 20 & 26,67 & 3,86 & 8 & 3,03 & 3,45 \\
\hline Rollinia maritima & 5 & 119 & 16,67 & 2,42 & 8 & 3,03 & 2,72 \\
\hline Asplenium sellowianum & 4 & 26 & 13,33 & 1,93 & 4 & 1,52 & 1,72 \\
\hline Heliotropium transalpinum & 4 & 43 & 13,33 & 1,93 & 4 & 1,52 & 1,72 \\
\hline Psychotria carthagenensis & 3 & 94 & 10,00 & 1,45 & 4 & 1,52 & 1,48 \\
\hline Cestrum strigilatum & 3 & 107 & 10,00 & 1,45 & 3 & 1,14 & 1,29 \\
\hline Desmodium affine & 3 & 19 & 10,00 & 1,45 & 3 & 1,14 & 1,29 \\
\hline Mesadenella cuspidata & 3 & 5 & 10,00 & 1,45 & 3 & 1,14 & 1,29 \\
\hline Homolepis glutinosa & 2 & 42 & 6,67 & 0,97 & 3 & 1,14 & 1,05 \\
\hline Oxalis linarantha & 2 & 23 & 6,67 & 0,97 & 3 & 1,14 & 1,05 \\
\hline Aechmea recurvata & 2 & 19 & 6,67 & 0,97 & 2 & 0,76 & 0,86 \\
\hline Rumohra adiantiformis & 2 & 87 & 6,67 & 0,97 & 2 & 0,76 & 0,86 \\
\hline Piper dilatatum & 1 & 192 & 3,33 & 0,48 & 3 & 1,14 & 0,81 \\
\hline Anemia phyllitidis & 1 & 35 & 3,33 & 0,48 & 1 & 0,38 & 0,43 \\
\hline Commelina obliqua & 1 & 14 & 3,33 & 0,48 & 1 & 0,38 & 0,43 \\
\hline Coniza rivularis & 1 & 15 & 3,33 & 0,48 & 1 & 0,38 & 0,43 \\
\hline Drymaria cordata & 1 & 28 & 3,33 & 0,48 & 1 & 0,38 & 0,43 \\
\hline Elephantopus mollis & 1 & 18 & 3,33 & 0,48 & 1 & 0,38 & 0,43 \\
\hline Hapalorchis micranthus & 1 & 6 & 3,33 & 0,48 & 1 & 0,38 & 0,43 \\
\hline Ocimum selloi & 1 & 18 & 3,33 & 0,48 & 1 & 0,38 & 0,43 \\
\hline Oxalis articulata & 1 & 8 & 3,33 & 0,48 & 1 & 0,38 & 0,43 \\
\hline Peperomia blanda & 1 & 14 & 3,33 & 0,48 & 1 & 0,38 & 0,43 \\
\hline Peperomia caulibarbis & 1 & 11 & 3,33 & 0,48 & 1 & 0,38 & 0,43 \\
\hline Tradescantia anagallidea & 1 & 6 & 3,33 & 0,48 & 1 & 0,38 & 0,43 \\
\hline Tradescantia crassula & 1 & 3 & 3,33 & 0,48 & 1 & 0,38 & 0,43 \\
\hline
\end{tabular}

(*) Incluindo Pseudechinolaena polystachya, presente eventualmente.

deu a importância das famílias Annonaceae, Tiliaceae e Phytolaccaceae, monoespecíficas neste levantamento, ao contrário de Commelinaceae e Rubiaceae que se destacaram pelo número de espécies e não pelo valor de importância.

Entre as espécies mais freqüentes sobressaíramse Carex sellowiana, presente em todas as unidades amostrais, Oplismenus hirtellus (amostrada conjuntamente com Pseudechinolaena polystachya devido à grande semelhança vegetativa) e Spathicarpa hastifolia. Considerando, além destas, as herbáceas Chaptalia nutans, Tradescantia fluminensis e os arbustos Pavonia sepium e Justicia brasiliana somam-se $60,8 \%$ das freqüências relativas da área amostrada, enquanto que 13 espécies (37\%), amostradas uma única vez, constituem apenas $6,28 \%$ deste total.

A espécie mais freqüente, Carex sellowiana, também apresentou a maior cobertura. Apenas 14\% das espécies apresentaram valores de cobertura relativa superior a cinco, sendo que a maior parte $(45,7 \%)$ teve valores inferiores a um. A cobertura total das sinúsias herbácea e arbustiva foi de aproximadamente $40 \%$ da área amostrada. 


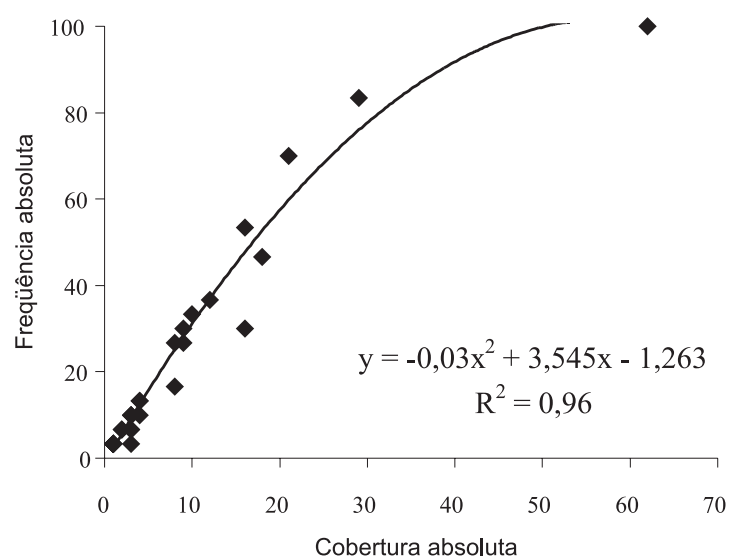

Figura 4. Relação entre freqüência absoluta e cobertura absoluta das espécies herbáceas e arbustivas na floresta de Morro Grande, Viamão, RS.

A relação entre freqüência absoluta e cobertura absoluta (figura 4) mostrou uma tendência polinomial em vista, basicamente, do ponto referente à Carex sellowiana, que se mostra isolado à direita do gráfico. Sem considerar a espécie Carex sellowiana, esta tendência seria fortemente linear (coeficiente de Pearson $=0,97$ ).

A estrutura vertical das sinúsias estudadas é verificada na figura 5 , onde se observa a presença de dois estratos, nitidamente separados, no interior da floresta de Morro Grande. O número de registros de alturas máximas no estrato herbáceo, considerado

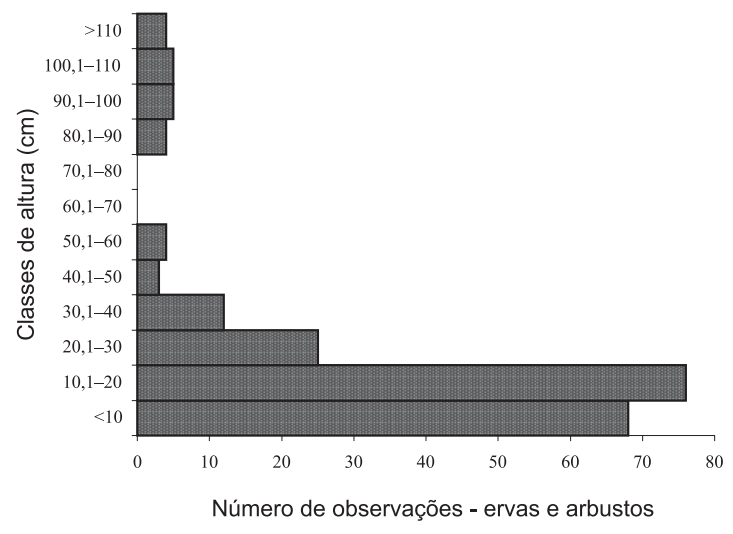

Figura 5. Proporção do número de observações da altura máxima das espécies herbáceas e arbustivas, em classes de altura a intervalos de $10 \mathrm{~cm}$, na floresta de Morro Grande, Viamão, RS.

até $20 \mathrm{~cm}$, foi superior ao arbustivo. A partir de todos os registros realizados, $69,9 \%$ tiveram até $20 \mathrm{~cm}$ de altura, tamanhos intermediários ( $>20$ até $60 \mathrm{~cm}$ ) perfizeram $21,36 \%$ e apenas $8,7 \%$ ultrapassaram $60 \mathrm{~cm}$ de altura. A espécie Justicia brasiliana apresentou a altura máxima registrada na área $(222 \mathrm{~cm})$.

Os índices de Shannon (H') e eqüidade (E) estimados para o componente herbáceo-arbustivo na floresta de Morro Grande foram 2,976 e 0,837, respectivamente. Numa avaliação separada por sinúsia, respectivamente herbácea e arbustiva, os resultados estimados foram 2,514 e 2,055 para o índice

Tabela 3: Comparação da diversidade de sinúsias herbáceo-arbustivas e herbáceas em comunidades florestais do Rio Grande do Sul, com indicação da área total amostrada $\left(\mathrm{m}^{2}\right)$, riqueza de espécies $(\mathrm{S})$, somatório da presença das espécies nos levantamentos ( $p p i)$ e índice de diversidade de Shannon (H'). A avaliação das diferenças pelo teste $t$ foram sempre em relação ao presente estudo, onde ** $(\mathrm{P}>0,001) ; *(\mathrm{P}>0,05) ;{ }^{\text {ns }}(\mathrm{P}<0,05)$.

\begin{tabular}{|c|c|c|c|c|c|c|c|}
\hline Sinúsia & Comunidades & Coordenadas & Área & $\mathrm{S}$ & $\Sigma p i$ & $\mathrm{H}^{\prime}$ & Fonte \\
\hline \multirow[t]{5}{*}{ Herbáceo-arbustiva } & Morro Grande & $30^{\circ} 05^{\prime} \mathrm{S}$ e $50^{\circ} 50^{\prime} \mathrm{W}$ & 120 & 36 & 207 & 2,976 & (1) \\
\hline & Canela & $29^{\circ} 23^{\prime} \mathrm{S}$ e $50^{\circ} 41^{\prime} \mathrm{W}$ & 600 & 40 & 178 & $3,322 * *$ & (2) \\
\hline & Rolante & $29^{\circ} 35^{\prime} \mathrm{S}$ e $50^{\circ} 26^{\prime} \mathrm{W}$ & 600 & 36 & 244 & $3,165 *$ & (2) \\
\hline & Morro do Coco & $30^{\circ} 16^{\prime} \mathrm{S}$ e $51^{\circ} 02^{\prime} \mathrm{W}$ & 720 & 29 & 171 & $2,948 \mathrm{~ns}$ & (3) \\
\hline & Parobé & $29^{\circ} 41^{\prime} \mathrm{S}$ e $50^{\circ} 51^{\prime} \mathrm{W}$ & 600 & 23 & 203 & $2,785 *$ & (2) \\
\hline \multirow[t]{5}{*}{ Herbácea } & Morro Grande & $30^{\circ} 05^{\prime} \mathrm{S}$ e $50^{\circ} 50^{\prime} \mathrm{W}$ & 120 & 26 & 150 & 2,514 & (1) \\
\hline & E. E. Aracuri & $28^{\circ} 13^{\prime} \mathrm{S}$ e $51^{\circ} 10^{\prime} \mathrm{W}$ & 120 & 20 & 253 & $2,688^{\mathrm{ns}}$ & (4) \\
\hline & Três Cachoeiras ${ }^{\mathrm{m}}$ & $29^{\circ} 20^{\prime} \mathrm{S}$ e $48^{\circ} 18^{\prime} \mathrm{W}$ & 600 & 17 & 110 & $2,388^{\mathrm{ns}}$ & $(5)$ \\
\hline & São João & $29^{\circ} 19^{\prime} \mathrm{S}$ e $49^{\circ} 47^{\prime} \mathrm{W}$ & 800 & 14 & 103 & $2,280 *$ & (6) \\
\hline & Três Cachoeiras ${ }^{b}$ & $29^{\circ} 20^{\prime} \mathrm{S}$ e $48^{\circ} 18^{\prime} \mathrm{W}$ & 600 & 16 & 93 & $2,271 *$ & (5) \\
\hline
\end{tabular}

m estande de solo mal drenado, ${ }^{b}$ estande de solo bem drenado. Fontes: (1) Presente estudo, (2) Diesel 1991, (3) Knob 1978, (4) Cestaro et al. 1986, (5) Citadini-Zanette 1984, (6) Citadini-Zanette \& Baptista 1989. 
de Shannon e 0,781 e 0,892 para a eqüidade. Uma comparação da diversidade do componente herbáceoarbustivo ou apenas das herbáceas terrícolas de comunidades florestais (tabela 3) mostrou diferenças significativas entre os valores encontrados na floresta de Morro Grande e outras localidades do Rio Grande do Sul.

\section{Discussão}

A comunidade herbácea e arbustiva terrícola da floresta costeira de Morro Grande está entre as mais ricas em espécies do sul do Brasil, apesar da diferença dos métodos aplicados, tanto em relação à área de amostragem quanto aos critérios de inclusão (Baptista \& Irgang 1972, Knob 1978, Citadini-Zanette 1984, Cestaro et al. 1986, Citadini-Zanette \& Baptista 1989, Diesel 1991, Dorneles \& Negrelle 1999). Assim como na floresta de Morro Grande, as comunidades florestais de Canela e Rolante, no vale do Rio dos Sinos (Diesel 1991) e da Reserva Volta Velha, no litoral catarinense (Dorneles \& Negrelle 1999) apresentaram mais de 30 espécies em amostragens do componente herbáceo-arbustivo. Por outro lado, as sinúsias herbáceas terrícolas de mata atlântica, próxima a Torres, apresentam número relativamente baixo de espécies, inferiores a 20 (Citadini-Zanette 1984, Citadini-Zanette \& Baptista 1989). Um fator limitante da riqueza e abundância de espécies herbáceas terrícolas em florestas mais densas, especialmente quando formadas por espécies arbóreas perenifólias, é atribuído à menor incidência de luz no ambiente do sub-bosque (Whittaker 1975, Braun-Blanquet 1979, Grime 1979).

De modo geral, as famílias amostradas apresentam poucas espécies, de uma a quatro, excepcionalmente sete, como verificado para Orchidaceae em uma comunidade herbácea sob solo bem drenado no município de Três Cachoeiras, anteriormente Torres, (Citadini-Zanette 1984) e Rubiaceae, considerando arbustos e herbáceas terrícolas amostradas no litoral catarinense (Dorneles \& Negrelle 1999). Entre as famílias mais ricas, Piperaceae, Poaceae e Asteraceae também têm maior número de espécies na floresta de Aracuri, na região do planalto das Araucárias (Cestaro et al. 1986), no Morro do Coco, situado na região do escudo sul-rio-grandense, próximo a Porto Alegre (Knob 1978) e, juntamente com Rubiaceae e Pteridaceae, nas florestas da bacia do Rio dos Sinos, na borda do planalto da Serra Geral (Diesel 1991).
Além destas, cabe colocar o destaque de Orchidaceae, principalmente, nas comunidades florestais situadas no norte do Rio Grande do Sul (Citadini-Zanette 1984, Citadini-Zanette \& Baptista 1989) e em Santa Catarina (Dorneles \& Negrelle 1999), onde também aparecem Araceae e Bromeliaceae como representativas da sinúsia herbácea.

Em trabalhos que envolvem herbáceas e arbustos terrícolas florestais do sul do Brasil é verificado um número maior de espécies herbáceas que arbustivas (Knob 1978, Diesel 1991, Dorneles \& Negrelle 1999). É possível que a maior plasticidade nas formas de vida encontradas em espécies herbáceas possa contribuir com este aspecto, uma vez que o aumento da importância de hemicriptófitas em florestas subtropicais é atribuído às espécies herbáceas terrícolas (Cain et al. 1956).

Entre as herbáceas terrícolas florestais, o maior número de espécies hemicriptófitas, como verificado no presente estudo, também foi observado no litoral norte do Rio Grande do Sul por Citadini-Zanette (1984) e Citadini-Zanette \& Baptista (1989), e em uma floresta com araucária por Cestaro et al. (1986). Nesta última, considerando as formas de crescimento, os autores atribuíram a maior participação de hemicriptófitas reptantes à presença de gado, principalmente pela capacidade de reprodução vegetativa, que permite maior resistência ao pisoteio e pastejo. Em Morro Grande, esta atribuição também pode ser considerada, pois foi constatada a presença eventual de gado em um dos fragmentos florestais.

Uma característica interessante foi a presença de Aechmea recurvata, Rumohra adiantiformis, Peperomia pereskiaefolia e P. caulibarbis, espécies comumente epífitas, inclusive nos fragmentos florestais estudados (Breier 1999), enraizadas no chão da floresta de Morro Grande. Este aspecto parece estar associado às condições de maior luminosidade e presença de substrato apropriado, comum em matas de restinga litorânea (Waechter 1985). A presença de 'epífitos caídos' crescendo no chão da floresta também é associada como uma estratégia de forma biológica destas espécies, denominadas como 'herbáceas terrestres facultativas' (Poulsen \& Balslev 1991).

$\mathrm{Na}$ estrutura vertical da floresta de Morro Grande, a presença de um estrato herbáceo aparentemente mais denso deve-se também ao registro de muitas espécies arbustivas baixas, como Triumfetta semitriloba, e subarbustivas, como Ocimum selloi, 
Pavonia sepium e Petiveria alliacea. Apenas alguns indivíduos arbustivos esparsos de Psychotria carthagenensis, Cestrum strigilatum, Justicia brasiliana e Piper dilatatum ultrapassaram $80 \mathrm{~cm}$ de altura, formando o estrato arbustivo. Em outras regiões do Rio Grande do Sul há um registro contínuo de alturas até 1,20 m para espécies herbáceas e arbustivas e a presença de alguns arbustos com até 3,20 m de altura (Diesel 1991). A baixa estatura geral das espécies arbustivas pode estar associada às condições edáficas de caráter mais xerofítico dessa floresta, conforme também observou Breier (1999) ao verificar a baixa diversidade de epífitos vasculares na floresta de Morro Grande. Em florestas mais úmidas, a maioria das espécies herbáceas terrícolas têm em média até 50 ou $70 \mathrm{~cm}$ de altura (CitadiniZanette 1984, Poulsen \& Balslev 1991, Dorneles \& Negrelle 1999).

Carex sellowiana, que se destacou na comunidade herbáceo-arbustiva da floresta de Morro Grande pelos altos valores de cobertura, apesar do seu pequeno porte, se distribui geograficamente pelos estados do sul do Brasil, Uruguai e Argentina, sendo freqüentemente citada para o interior de florestas, todavia com abundância restrita (Knob 1978, Cestaro et al. 1986, Diesel 1991).

O destaque na cobertura ou densidade de uma só espécie para o estrato herbáceo, também foi verificado em outras comunidades florestais, como Nidularium innocentii nos levantamentos de Citadini-Zanette (1984) e Dornelles \& Negrele (1999), Oxalis linarantha na amostragem realizada em Rolante por Diesel (1991), e ainda um grupo de gramíneas (Panicum ovuliferum, Pseudochinolaena polystachya e Oplismenus hirtellus) na floresta de Aracuri, por Cestaro et al. (1986). Na floresta de Morro Grande, Oplismenus hirtellus e Pseudochinolaena polystachya também se mostram importantes e esta importância pode estar associada à antropização gerada pela presença do gado, uma vez que se caracterizam como hemicriptófitas reptantes e apresentam frutos epizoocóricos, facilmente transportados junto às patas destes animais (Smith et al. 1982).

A diversidade de comunidades herbáceas e herbáceo-arbustivas florestais no Rio Grande do Sul (tabela 3) revela valores semelhantes e significativamente diferentes, superiores e inferiores, a de Morro Grande. As comunidades de Morro do Coco, Aracuri, e Três Cachoeiras (estande brejoso), cujos valores de diversidade não diferem da floresta de Morro Grande, apesar dos aspectos fisiográficos bastante distintos, apresentam características limitantes que podem estar condicionando a diversidade das sinúsias herbácea e arbustiva. $\mathrm{O}$ Morro do Coco, compreendido na região dos morros graníticos de Porto Alegre, apresenta uma vegetação condicionada por fatores pedológicos, especialmente a pouca profundidade do solo (Aguiar et al. 1986, Backes 1999). Solos rasos e solos arenosos bem drenados, como na floresta de Morro Grande, podem ocasionar um déficit hídrico às espécies, principalmente durante o verão. Na comunidade de Três Cachoeiras, foi verificada a pouca drenagem do solo e a conseqüente baixa disponibilidade de oxigênio às raízes, aliada ao oligotrofismo destes solos (Citadini-Zanette 1984), enquanto na comunidade de Aracuri tem-se um clima mais frio, típico da região do planalto, associado ao caráter semidecidual da floresta e a pressão seletiva sofrida pela presença do gado em períodos anteriores (Waechter et al. 1984, Cestaro et al. 1986).

A maior diversidade do componente herbáceoarbustivo foi estimada para a comunidade de Canela, uma floresta ombrófila mista em contato com a floresta estacional semidecidual. A alta diversidade pode estar relacionada à maior área amostrada e à variedade de ambientes observada no interior da área, inclusive com afloramentos rochosos (Diesel 1991). As comunidades de Rolante e Parobé identificam-se como florestas estacionais semideciduais, sendo a primeira descrita num estágio de regeneração secundária com estratos pouco definidos e alta luminosidade no subbosque, e a segunda (cuja diversidade herbáceoarbustiva foi a menor) como uma floresta de terras baixas, com uma estratificação bem definida e árvores de grande porte (Diesel 1991).

A menor diversidade da sinúsia herbácea foi observada para as comunidades florestais do litoral norte (São João e Três Cachoeiras), cuja região apresenta a maior diversidade florestal do estado para os componentes arbóreo (Jarenkow 1994) e epifítico vascular (Waechter 1998), influenciadas pela proximidade das comunidades da mata atlântica do litoral catarinense.

Outros trabalhos direcionados às comunidades herbáceas e arbustivas florestais descrevem maior riqueza e densidade de espécies herbáceas em florestas secas que em florestas úmidas (Gentry \& Dodson 1987), ou ainda maior diversidade arbustiva 
em áreas de floresta secundária do que em florestas primárias, em vista da maior intensidade de luz disponível (Laska 1997). Além destes, fatores como a interferência antrópica, drenagem do solo (Turner et al. 1996), variações na declividade do terreno e altitudes extremas (Poulsen 1996, Poulsen \& Pendry 1995) também preponderam nos padrões de diversidade das sinúsias herbácea e arbustiva florestais.

Pelas informações anteriores pode-se sugerir que a diversidade do componente herbáceo e herbáceoarbustivo é relativamente maior em florestas que dispõem de vários ambientes diferentes (Canela) e em florestas mais secas e com maior incidência de luz, seja pelo porte relativamente baixo (Morro Grande, Morro do Coco), seja pelo caráter secundário (Parobé). Nas florestas mais úmidas e bem preservadas a diversidade tende a ser menor (Três Cachoeiras, São João e Rolante). Trabalhos futuros, voltados a este assunto, poderão inferir mais adequadamente sobre o grau de influência destes aspectos na diversidade e abundância dos estratos inferiores de comunidades florestais.

Agradecimentos - Ao Programa de Pós-Graduação em Botânica da UFRGS, pela oportunidade de realização deste trabalho. À CAPES, pela bolsa de mestrado concedida à primeira autora. Aos colegas Silvia Venturi e Tiago B. Breier, pela companhia nos trabalhos de campo. Aos pesquisadores Adriana Güglieri, Ilsi J. Boldrini, Lilian Mentz, Rosana M. Senna, pela contribuição na identificação taxonômica das espécies registradas.

\section{Referências bibliográficas}

AGUIAR, L.W., MARTAU, L., SOARES, Z.F., MARIATH, J.E. \& KLEIN, R.M. 1986. Estudo preliminar da flora e vegetação de morros graníticos da região da Grande Porto Alegre, Rio Grande do Sul, Brasil. Iheringia 34:3-38.

BACKES, A. 1999. Ecologia da floresta do Morro do Coco, Viamão, RS. Pesquisas, série Botânica 49:5-30.

BAPTISTA, L.R.M. \& IRGANG, B.E. 1972. Nota sobre a composição florística de uma comunidade florestal dos arredores de Porto Alegre. Iheringia 16:3-8.

BRAUN-BLANQUET, J. 1979. Fitosociologia: bases para el estudio de las comunidades vegetales. H. Blume, Madrid.

BREIER, T.B. 1999. Florística e ecologia de epífitos vasculares em uma floresta costeira subtropical. Dissertação de mestrado, Universidade Federal do Rio Grande do Sul, Porto Alegre.

CAIN, S.A., CASTRO, G.M.C., PIRES, J.M. \& SILVA, N.T. 1956. Application of some phytosociological techniques to Brazilian rain forest. American Journal of Botany 43:911-941.

CAUSTON, D.R. 1988. Introduction to vegetation analysis. Unwin Hyman, London.
CESTARO, L.A., WAECHTER, J.L. \& BAPTISTA, L.R.M. 1986. Fitossociologia do estrato herbáceo da mata de araucária da Estação Ecológica de Aracuri, Esmeralda, RS. Hoehnea 13:59-72.

CITADINI-ZANETTE, V. \& BAPTISTA, L.R.M. 1989. Vegetação herbácea terrícola de uma comunidade florestal em Limoeiro, município de Torres, Rio Grande do Sul, Brasil. Boletim do Instituto de Biociências da UFRGS 45:1-87.

CITADINI-ZANETTE, V. 1984. Composição florística e fitossociologia da vegetação herbácea terrícola de uma mata de Torres, Rio Grande do Sul, Brasil. Iheringia 32:2362.

CORDAZZO, C.V. \& SEELIGER, U. 1987. Composição e distribuição da vegetação nas dunas costeiras ao sul de Rio Grande (RS). Ciência e Cultura 39:321-324.

CRONQUIST, A. 1988. The evolution and classification of flowering plants. 2ed. The New York Botanical Garden, New York.

DELANEY, P.J.V. 1965. Fisiografia e geologia de superfície da planície costeira do Rio Grande do Sul. Escola de Geologia, UFRGS, Porto Alegre. (publicação especial n. ${ }^{\circ}$ 6).

DIESEL, S. 1991. Estudo fitossociológico herbáceo/arbustivo da mata ripária da bacia hidrográfica do Rio dos Sinos, RS. Pesquisas, série Botânica 42:201-257.

DILlENBURG, L.R., WAECHTER, J.L. \& PORTO, M.L. 1992. Species compositon and structure of a sandy coastal plain forest in northern Rio Grande do Sul, Brazil. In Coastal plant communities of Latin America (U. Seeliger, ed.). Academic Press Inc., São Diego, p.349-366.

DORNELES, L.P.P. \& NEGRELE, R.R.B. 1999. Composição florística e estrutura do compartimento herbáceo de um estágio sucessional avançado da Floresta Atlântica, no sul do Brasil. Biotemas 12:7-30.

GENTRY, A.H. 1992. Tropical forest biodiversity: distributional patterns and their conservational significance. Oikos 63:19-28.

GENTRY, A.H. \& DODSON, C. 1987. Contribuition of nontrees to species richness of a tropical rain forest. Biotropica 19:149-156.

GIVNISH, T.J. 1986. Biomechanical constraints on crown geometry in forest herbs. In On the economy of plant form and function (T.J. Givnish, ed.). Cambridge University Press, New York, p.525-583.

GRIME, J.P. 1979. Plant strategies and vegetation processes. John Wiley \& Sons, Chichester.

HERRMANN, M.L.P. \& ROSA, R.O. 1990. Relevo. In Geografia do Brasil - Região Sul (IBGE), v.2, IBGE, Rio de Janeiro, p.55-84.

JARENKOW, J.A. 1994. Estudo fitossociológico comparativo entre duas áreas com mata de encosta no Rio Grande do Sul. Tese de doutorado, Universidade Federal de São Carlos, São Carlos.

KNOB, A. 1978. Levantamento fitossociológico da formação mata do Morro do Coco, Viamão, Rio Grande do Sul. Iheringia 23:65-108.

LASKA, M.S. 1997. Structure of understory shrub assemblages in adjacent secondary and old growth tropical wet forests, Costa Rica. Biotropica 29:29-37.

LEMOS, R.C., AZOLIM, M.A.D., ABRÃO, P.U.R. \& SANTOS, M.C.L. 1973. Levantamento de reconhecimento dos solos do estado do Rio Grande do Sul. Ministério da Agricultura, Recife (Boletim Técnico $n^{\circ} 30$ ). 
MAGURRAN, A.E. 1988. Ecological diversity and its measurement. Croom Helm Limited, London.

MARTINS, F.R. 1993. Estrutura de uma floresta mesófila. 2 ed. Universidade Estadual de Campinas, Campinas.

MORENO, J.A. 1961. Clima do Rio Grande do Sul. Secretaria da Agricultura, Porto Alegre.

MOTA, F.S., GOEDERT, C.O., LOPES, N.F., GARCEZ, J.R.B. \& GOMES, A.S. 1970. Balanço hídrico do Rio Grande do Sul. Pesquisa Agro-pecuária Brasileira 5:1-27.

MUELLER-DOMBOIS, D. \& ELLENBERG, H. 1974. Aims and methods of vegetation ecology. John Wiley \& Sons, New York.

MÜLLER, S.C. 1999. Estrutura sinusial e relações florísticas dos componentes herbáceo e arbustivo de uma floresta costeira subtropical. Dissertação de mestrado, Universidade Federal do Rio Grande do Sul, Porto Alegre.

NIMER, E. 1979. Climatologia do Brasil. IBGE-SUPREN, Rio de Janeiro.

PFADENHAUER, J. 1980. Die Vegetation der Küstendünen von Rio Grande do Sul, Südbrasilien. Phytocoenologia $8: 321-364$

PIELOU, E.C. 1969. An introduction to mathematical ecology. Wiley-Interscience, New York.

PORTO, M.L. \& DILlENBURG, L.R. 1986. Fisionomia e composição florística de uma mata de restinga da Estação Ecológica do Taim, Brasil. Ciência e Cultura 38:12281236.

POULSEN, A.D. \& BALSLEV, H. 1991. Abundance and cover of ground herbs in an Amazonian rain forest. Journal of Vegetation Science. 2:315-322.

POULSEN, A.D. \& PENDRY, C.A. 1995. Inventories of ground herbs at three altitudes on Bukit Belalong, Brunei, Borneo. Biodiversity and Conservation 4:745-757.

POULSEN, A.D. 1996. Species richness and density of ground herbs within a plot of lowland rain forest in norh-west Borneo. Journal of Tropical Ecology 12:177-190.

RAMBO, B. 1954. História da flora do litoral riograndense. Sellowia 6:113-172.

RICHARDS, P.W. 1952. The tropical rain forest: a ecological study. University Press, Cambridge.

RIZZINI, C.T. 1997. Tratado de fitogeografia do Brasil: aspectos ecológicos, sociológicos e florísticos. 2ed. Âmbito Cultural, São Paulo.

ROSSONI, M.G. \& BAPTISTA, L.R.M. 1994/1995. Composição florística da Mata de Restinga, Balneário Rondinha, Arroio do Sal, RS, Brasil. Pesquisas série Botânica 45:115-131.

SENNA, R.M. \& WAECHTER, J.L. 1997. Pteridófitas de uma floresta com araucária. I. Formas biológicas e padrões de distribuição geográfica. Iheringia 48:41-58.

SMITH, L.B., WASSHAUSEN, D.C. \& KLEIN, R.M. 1982. Gramíneas - gêneros: Deschampsia até Pseudechinolaena. Flora Ilustrada Catarinense (Gram): 443-906.
TRYON, R.M. \& TRYON, A.F. 1982. Ferns and allied plants with special reference to tropical America. SpringerVerlag, New York.

TURNER, I.M., TAN, H.T.W. \& CHUA, K.S. 1996. Relatonships between herb layer and canopy composition in a tropical rain forest successional mosaic in Singapore. Journal of Tropical Ecology 12:843-851.

VEBLEN, T.T., VEBLEN, A.T. \& SCHLEGEL, F.M. 1979. Understorey patterns in mixed evergreen-deciduous Nothofagus forests in Chile. Journal of Ecology 67:809-823.

VELOSO, H.P. \& KLEIN, R.M. 1963. As comunidades e associações vegetais da mata pluvial do sul do Brasil - IV. As associações situadas entre o Rio Tubarão (SC) e a Lagoa dos Barros (RS). Sellowia 15:57-114.

VENTURI, S. 2000. Florística e fitossociologia do componente apoiante-escandente em uma floresta costeira do sul do Brasil. Dissertação de mestrado, Universidade Federal do Rio Grande do Sul, Porto Alegre.

VILLWOCK, J.A. 1984. Geology of the coastal province of Rio Grande do Sul, Southern Brazil. A synthesis. Pesquisas série Geológica 16:5-49.

WAECHTER, J.L., CESTARO, L.A. \& MiOTTO, S.T.S. 1984. Vegetation types in the Ecological Station of Aracuri, Esmeralda, Rio Grande do Sul, Brazil. Phytocoenologia 12:261-269.

WAECHTER, J.L. 1985. Aspectos ecológicos da vegetação de restinga do Rio Grande do Sul, Brasil. Comunicações do Museu de Ciências da PUCRS, série Botânica 33:49-68.

WAECHTER, J.L. 1990. Comunidades vegetais das restingas do Rio Grande do Sul. In Anais do II Simpósio de Ecossistemas da costa sul e sudeste brasileira: estrutura, função e manejo (S. Watanabe, coord.). ACIESP, São Paulo, v. 3:228-248.

WAECHTER, J.L. 1998. Epiphytic orchids in eastern subtropical South America. In Proceedings of the $15^{\text {th }}$ World Orchid Conference, Rio de Janeiro, Brazil, 1996 (C.E.B. Pereira, ed.). Naturalia, Turriers, p.332-341.

WAECHTER, J.L. \& JARENKOW, J.A. 1998. Composição e estrutura do componente arbóreo nas matas turfosas do Taim, Rio Grande do Sul. Biotemas 11:45-69.

WAECHTER, J.L., MÜLLER, S.C., BREIER, T.B. \& VENTURI, S. 2000. Estrutura do componente arbóreo em uma floresta subtropical de planície costeira interna. In Anais do V Simpósio de Ecossistemas Brasileiros: Conservação (S. Watanabe, coord.). ACIESP, Vitória, v. 3, p.92-112.

WHITTAKER, R.H. 1972. Evolution and measurement of species diversity. Taxon 21:213-251.

WHITTAKER, R.H. 1975. Communities and Ecosystems. 2 ed. Macmillan, New York. 